\title{
Profound Leptomeningeal and Intramedullary Abnormalities in Bing-Neel Syndrome
}

\section{Joy Zhuo Ding, Ryan Gotfrit, Santanu Chakraborty}

Keywords: Hematology, Neurology, Internal Medicine, Neuroradiology, Psychiatry, Bing-Neel syndrome, Waldenstrom macroglobulinemia
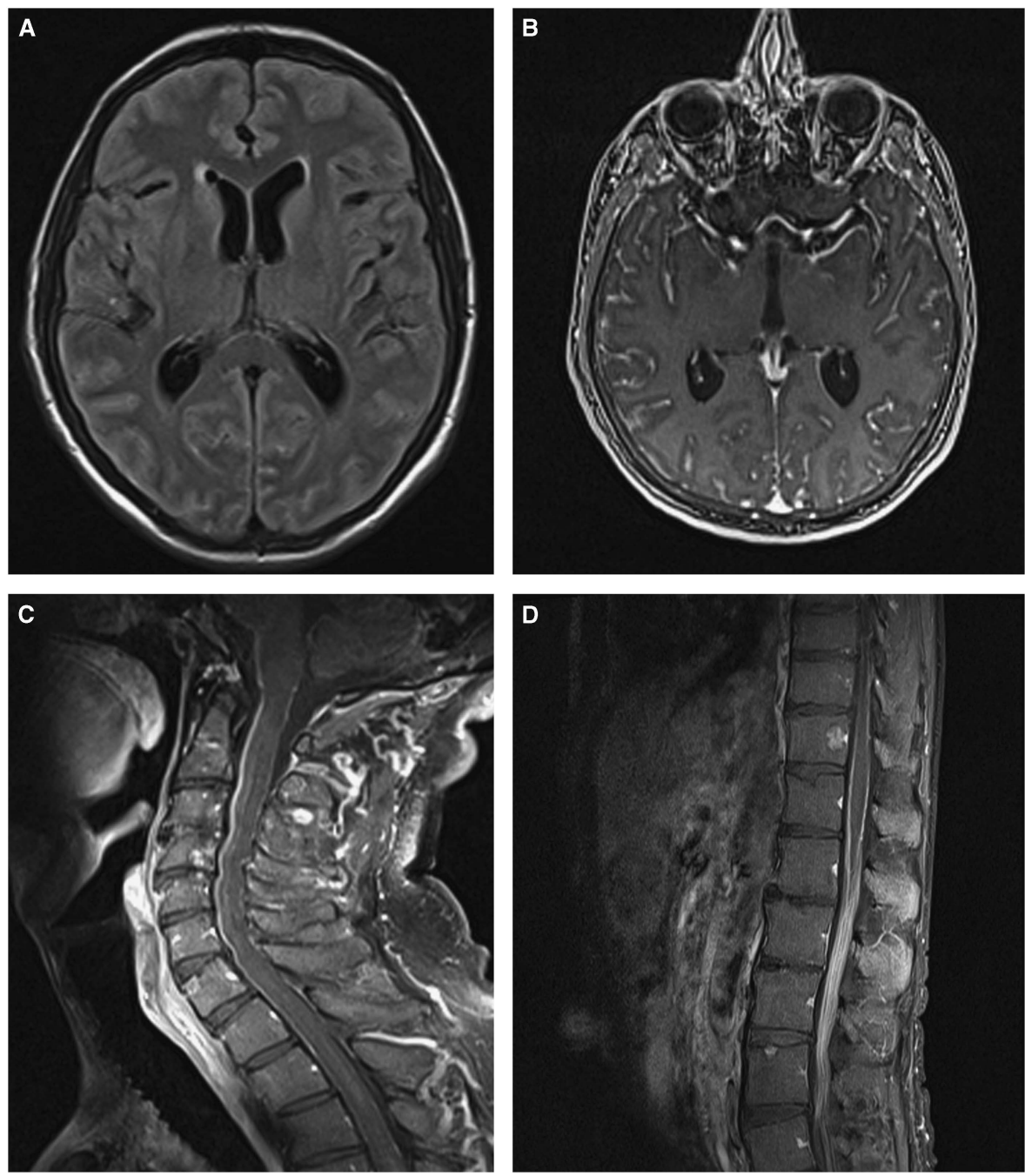

Figure 1: (A) Diffuse sulcal hyperintensities on FLAIR. (B) After gadolinium administration, there is extensive leptomeningeal enhancement in the brain, $(C)$ cervical spine and $(D)$ cauda equina.

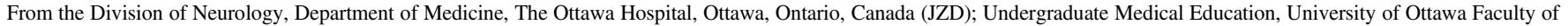
Medicine, Ottawa, Ontario, Canada (RG); Department of Medical Imaging, The Ottawa Hospital, Ottawa, Ontario, Canada (SC).

Received July 22, 2018. Date of Acceptance August 2, 2018

Correspondence to: S. Chakraborty, Department of Medical Imaging, The Ottawa Hospital Civic Campus, 1053 Carling Avenue, Ottawa, ON, Canada K1Y 4E9.

Email: schakraborty@toh.ca 

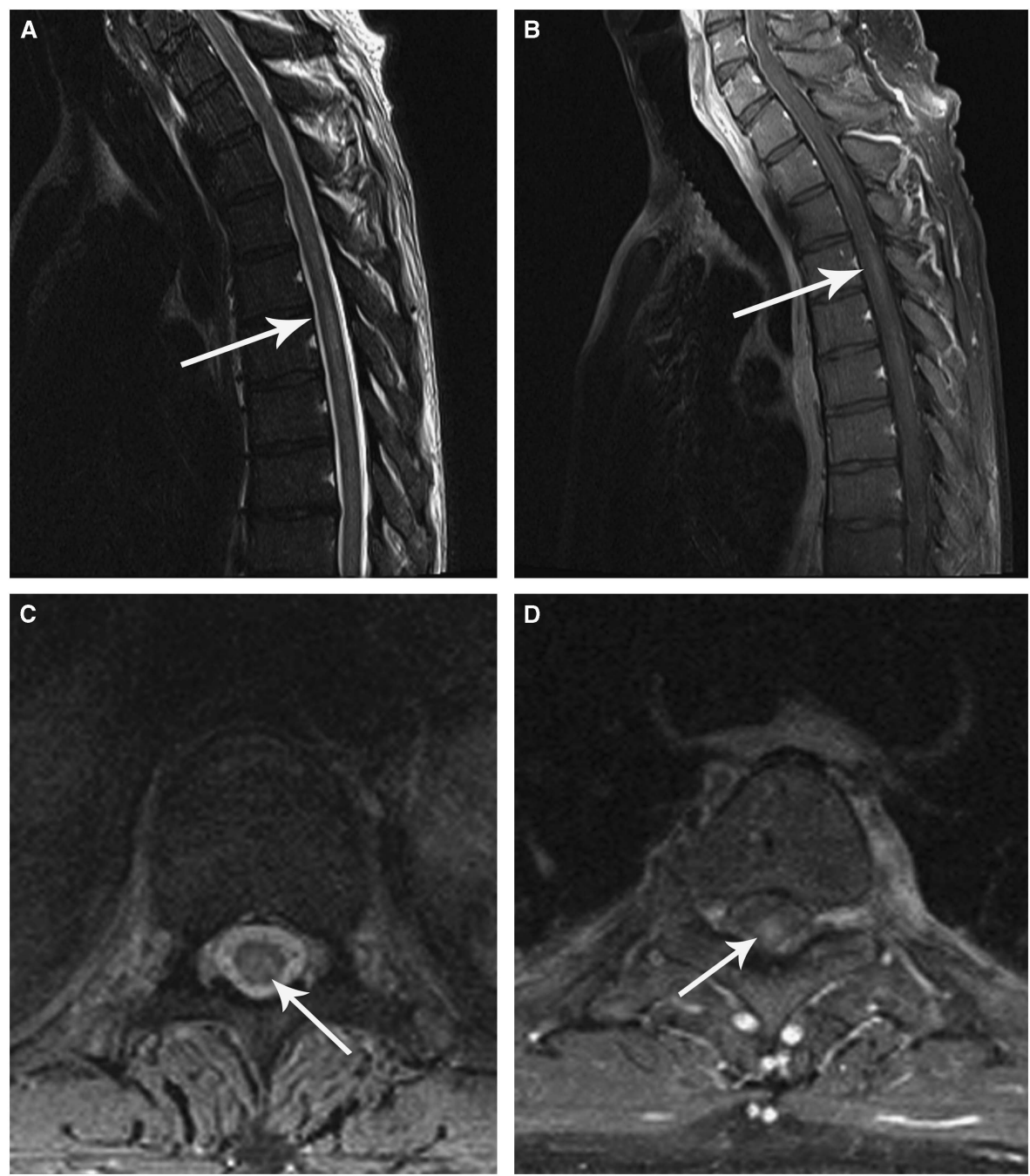

Figure 2: $(A, C)$ MRI of the spine showing longitudinally extensive intramedullary hyperintensity on $T 2 .(B, D)$ This lesion enhances with gadolinium.

A 52-year-old man with known Waldenstrom macroglobulinemia (WM) presented with acute psychosis and hallucinations. His neurologic examination was intact aside from abnormal mental status. He was initially admitted to psychiatry department for management of psychosis and hallucinations. Neurology was consulted to rule out organic cause of his persistent psychosis.

MRI showed extensive leptomeningeal enhancement of the entire brain, spinal cord and cauda equina (Figure 1). In addition, enhancing longitudinally extensive intramedullary $\mathrm{T} 2$ hyperintensity in the thoracic cord was noted (Figure 2). CSF showed markedly elevated protein $(6.5 \mathrm{~g} / \mathrm{L})$ and lymphocytic pleocytosis, and flow cytometry was positive for central nervous system (CNS) lymphoplasmacytic lymphoma consistent with Bing-Neel syndrome.

Bing-Neel syndrome is a rare presentation of WM. Waldenstrom macroglobulinemia is a rare B-cell-mediated immunoglobulin M-producing lymphoproliferative disorder accounting for $1-2 \%$ of non-Hodgkin's lymphoma. ${ }^{1}$ Bing-Neel syndrome is caused by infiltration of malignant B cells into the CNS, sometimes in the absence of systemic progression. ${ }^{2}$ Patients present with progressive symptoms over weeks or months, including headache, seizures, cognitive changes or cranial neuropathies from leptomeningeal involvement. ${ }^{2}$ They can also present with hyperviscosity syndrome leading to visual loss (retinal hemorrhage) or epistaxis. Treatment is similar to primary CNS lymphoma, with steroid therapy as induction, followed by blood-brain barrier penetrating chemotherapy (e.g., methotrexate, cytarabine and ibrutinib). ${ }^{2}$ Median survival for WM is estimated to be 7-12 years. ${ }^{2}$ The survival rate for Bing-Neel syndrome is reported as $71 \%$ at 5 years and $59 \%$ at 10 years. $^{3}$

Clinicians should remember that malignant B-cell infiltration to the CNS may lead to isolated psychiatric symptoms and should have low threshold for work-up of new psychosis or hallucinations in WM patients. In addition to leptomeningeal and intraparenchymal brain lesions, intramedullary spinal lesions may also be seen in Bing-Neel syndrome.

\section{ACKNOWLEDGMENTS}

None. 


\section{DisClOSURES}

JZD, RG and SC have nothing to disclose.

\section{Statement of Authorship}

JZD contributed to clinical care of the patient, case concept and drafting and revising the manuscript. RG was involved in drafting and revising the manuscript. SC was involved in imaging acquisition and drafting and revising the manuscript.

\section{REFERENCES}

1. Castillo JJ, D'Sa S, Lunn MP, et al. Central nervous system involvement by Waldenström macroglobulinaemia (Bing-Neel syndrome): a multi-institutional retrospective study. Br J Haematol. 2016;172(5):709-15.

2. Minnema MC, Kimby E, D'Sa S, et al. Guideline for the diagnosis, treatment and response criteria for Bing-Neel syndrome. Haematologica [Internet]. 2017;102(1):43-51.

3. Simon L, Fitsiori A, Lemal R, et al. Bing-Neel syndrome, a rare complication of Waldenström macroglobulinemia: analysis of 44 cases and review of the literature. A study on behalf of the French Innovative Leukemia Organization (FILO). Haematologica. 2015;100(12):1587-94. 